\title{
ESTONIAN AND FINNISH STUDENTS' EXPERIENCES ABOUT INTERNATIONAL CAREER GUIDANCE E-LEARNING COURSE
}

\author{
Kristi Kõiv ${ }^{1}$, Ari Jussila ${ }^{2}$, Outi Rantanen ${ }^{2}$, \& Triin Peitel $^{1}$ \\ ${ }^{1}$ University of Tartu, Institute of Education (Estonia) \\ ${ }^{2}$ Tampere University of Applied Sciences, School of Professional Techer Education, (Finland)
}

\begin{abstract}
The present study consists of a need for assessment of Estonian and Finnish university students' experiences of developed common career guidance international course as a part of teacher training programs in two higher education institutions - University of Tartu and Tampere University of Applied Sciences. The research was based on a survey developed on small sample of Estonian $(\mathrm{N}=19)$ and Finnish $(\mathrm{N}=9)$ students who participated in integrated e-learning platform lasting one academic semester. At the end of the course the collected data had been both quantitative and quantitative. The self-reported questionnaire for students consists of 13 questions about cognitive and learning skills concerning with participating in career guidance course; and for the qualitative approach as the concept mapping about the course as a base of data of quantitative content analysis. Results showed that the top learning experiences used during course by participants were collaborative work skills in international learning context and cognitive skills in the area of critical thinking as analyzing and evaluation of knowledges' in career guidance. Empirical findings provide evidence that course was suitable at enhancing students' academic skills and experiences.
\end{abstract}

Keywords: Career guidance, university students, one-group posttest research design.

\section{Introduction}

Career courses and other career interventions have an important role in preparing students for transitions throughout lifelong learning (Reardon, Lenz, Sampson, \& Peterson, 2017). Previous research had documented the efficacy of a career course as an intervention for university students. For example, reduction of participants negative traits (Oliver \& Spokane, 1988) and negative career thoughts (Osborn, Howard, \& Leierer, 2007; Reed, Reardon, Lenz, \& Leierer, 2001); increasement of positive traits (Peng, 2001) and self-concept (Carver \& Smart, 1985); and development of career development processes and career maturity (Clark \& Wayment, 2017; Freeman, Lenz, \& Reardon, 2017).

Understanding how university students learn about various aspects of career guidance course will also be important to analyze and consider how best to infuse curricula with information about career development. In the current study, the development and implementation of new common international career guidance course and the assessment of university students experiences about the targeted course took place after fulfillment this course. A research question was evoked: Do common international career guidance e-learning course is beneficial for Estonian and Finnish students' cognitive and learning skills?

The aim of this work was twofold: (1) to develop and implement a common international study course in the area of career guidance at two universities in Estonia and Finland; and (2) to describe participants' self-reported learning experiences after the end of this integrated e-learning course in two areas: learning experiences and academic (cognitive and learning) skills.

\section{Method}

\subsection{International career guidance e-learning course}

The developed common international e-learning course in the area of career guidance was a regular part of both participating countries' universities teacher training curriculum. The two credit point course addresses to (1) encourage and build understanding of the international context of career guidance, 
(2) identify cultural concepts and presumptions in the field of career guidance, and (3) familiarize learners to how and on what basis education and career guidance systems process in two participating countries. During 11-week semester the course exposes the target audience masters' degree students to a logical progression of topics intended to build knowledge's, skills and attitudes in the area career guidance systems in two targeted countries as a basis of international contexts. Each week's module requires students to study a topic including self-directed research, develop of personal reflections, engage with peers in online discussion boards, prepare groupwork and video-presentations.

At the end of the course, students were able to describe and compare the main aspects of their own and neighboring country's career system from international perspective, whereby the competence in understanding and applying concepts were measured through tests and completed homework assignments.

\subsection{Participants}

The research was conducted on a sample of all 28 participants of international career guidance course, with ages ranging between $21-33$ years $(\mathrm{M}=25.3, \mathrm{SD}=1.2)$. All participants were teacher training students at University of Tartu $(\mathrm{N}=19)$ and at Tampere University of Applied Sciences $(\mathrm{N}=9)$. Participation in the investigation was voluntary and anonymous, data confidentiality and other ethical aspects were assured.

\subsection{Study design and instruments}

A one group post-test pilot study design was used, and Estonian and Finnish university students completed post-questionnaires in the 11th weeks of their respective course. The self-reported questionnaire consists of 13 questions as short descriptions of two areas of academic skills. The investigation themes include: Cognitive skills (based on the typology: analyzing, evaluation, applying, understanding, remembering, and creating: Anderson \& Krathwohl, 2000) and learning skills (active learning, enjoyment of learning, group work, meaningful learning, intrinsic motivation, performance, and problem solving). This process resulted in a list with 13 single-answer items with a three-point scale, where students had to rate their level of agreement: Completely (3) Partly (2) and Not at all (1) with answering the question: What kind of skills I had during my studies in the area of the international course?

For the qualitative approach the concept mapping methodology was used in this study to answer the question: What kind of experiences I had during my studies in the area of the international course? with use of computer drawing program or free-hand drawings. Concept mapping as a research method was used to assess participants' experiences of a topic and data were analyzed using a quantitative content analysis.

\section{Results}

Students self-reported data of the pilot study showed that international career guidance courses had developed their cognitive skills connected with analyzing and evaluation of information as two aspects of critical thinking, whereby the same tendency was revealed analyzing qualitative data of the study (Figure 1, Table 1). In addition, significant difference using by t-tests were found at the level of 0.05 between the mean scores of students self-reported cognitive skills comparing analyzing and evaluation with remembering and creating (accordingly: $t=1.75 ; t=2.24 ; t=1.72 ; t=2.44$ ), showing that students evaluated their cognitive skills in the area of analyzing and evaluation higher than remembering and creating.

Also, group work and active learning skills were more highly evaluated by university students than self-assessment skills and intrinsic motivation (accordingly: $t=2.83, \mathrm{p}<.01 ; t=1.83, \mathrm{p}<.05 ; t=2.80$, $\mathrm{p}<.01 ; t=1.72, \mathrm{p}<.05)$, whereby other learning skills - meaningful learning, enjoyment of learning, problem solving and performance skills, were moderately evaluated abilities (Figure 1). 
Figure 1. Course participants self-reported learning and cognitive skills (means).

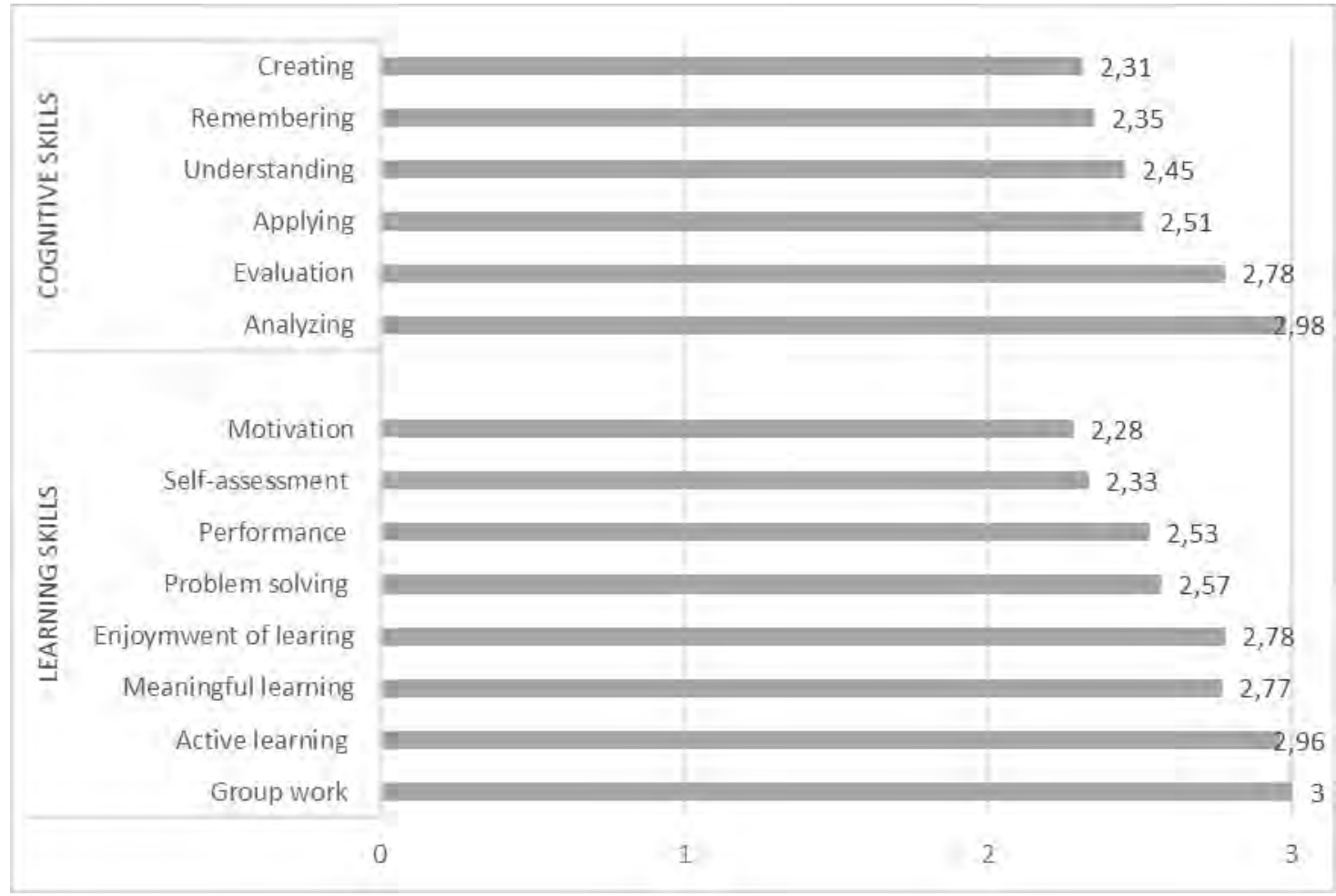

Table 1. Categories and subcategories of participants experiences about international common career guidance course.

\begin{tabular}{lll}
\hline Category & Subcategory & $\begin{array}{c}\text { Frequency } \\
\mathbf{\%}\end{array}$ \\
\hline Cognitive competence & Analyzing & $21 \%$ \\
& Evaluation and synthesis & $6 \%$ \\
& Applying & $5 \%$ \\
& Understanding & $4 \%$ \\
& Remembering & $3 \%$ \\
& Creation & $2 \%$ \\
Learning skills & & $1 \%$ \\
& Active learning & $17 \%$ \\
Social and emotional learning skills & Passive learning & $13 \%$ \\
& & $4 \%$ \\
& Development of collaborative learning & $28 \%$ \\
& Accept of different viewpoints and common values & $15 \%$ \\
& Valuing of learning experiences & $8 \%$ \\
& & $5 \%$ \\
Professional identity & & $6 \%$ \\
& Development of professional identity & $3 \%$ \\
& Self-assessment and reflection & $25 \%$ \\
& & $19 \%$ \\
& Rich/good international learning experience & $4 \%$ \\
& Common learning goals & $1 \%$ \\
& Wide context: school and workplace & $1 \%$ \\
\hline
\end{tabular}

Results from post-course qualitative data gathered by concept mapping showed that course participants' experiences were frequently connected with development of their social and emotional learning skills, especially with collaborative learning and active learning experiences with possibilities for value education - internalizing values. Also created good and rich international learning environment with common study aims was empathized by participants, but relatively lesser were expressed skills connected with development of professional identity and self-reflection/assessment (Table 1). 


\section{Conclusions}

The most relevant results of the study show that content of the course was highly evaluated as: (1) collaborative and active learning context with perceived possibilities for development of professional identity development; (2) high level academic cognitive skills of analyzing and evaluating information as components of critical thinking; and (3) possibilities for development of social and emotional learning skills (e.g. internalizing values). In contrast, intrinsic learning motivation and course flexibility in the area of practical orientation with possibilities for deeper self-assessment and reflection was perceived as critical factors for future development of the course.

In conclusion, findings of the pilot study imply preliminary results that the developed and applied international career guidance e-learning course as a part of regular teacher training curriculum at the higher education was suitable learning context for enriching participants' multi-dimensional academic skills and experiences in the area of career guidance.

\section{References}

Anderson, L. W., \& Krathwohl, D. R., et al (2000) A Taxonomy for Learning, Teaching, and Assessing: A Revision of Bloom's Taxonomy of Educational Objectives. New York: Allyn \& Bacon.

Carver, D. S., \& Smart, D. W. (1985). The effects of a career and self-exploration course for undecided freshmen. Journal of College Student Personnel, 26, 37-43.

Clark, T. S. C., \& Wayment, H. A. (2017). Integrating online career-development skills in a management course: Findings of increased career confidence and adult development. Journal of the Academy of Business Education, 18, 68-81.

Freeman, V. F., Lenz, J. G., \& Reardon, R. (2017). Career Course Impact on College Students' Career Decision and Affective States. VISTAS Online, 1-13.

Osborn, D. S., Howard, D. K., \& Leierer, S. J. (2007). The effect of a career development course on the dysfunctional career thoughts of racially and ethnically diverse college freshmen. The Career Development Quarterly, 55, 365-377.

Oliver, L. W., \& Spokane, A. R. (1988). Career-intervention outcome: What contributes to client gain? Journal of Counseling Psychology, 35, 447-462.

Peng, H. (2001). Comparing the effectiveness of two different career education courses on career decidedness for college freshmen: An exploratory study. Journal of Career Development, 28, $29-41$.

Reardon, R. C., Lenz, J. G., Sampson, J. P., Jr., \& Peterson, G. W. (2017). Career development and planning: A comprehensive approach. Dubuque, IA: Kendall Hunt.

Reed, C. A., Reardon, R. C, Lenz, J. G., \& Leierer, S. J. (2001). A cognitive career course: From theory to practice. The Career Development Quarterly, 50, 158-167. 